\title{
Multipoint identification of Enterobacteriaceae: Report of the British Society for Microbial Technology collaborative study
}

\author{
T G Winstanley, D I Limb, P F Wheat, C D Nicol
}

\begin{abstract}
Aims-To evaluate the accuracy and reproducibility of multipoint identification schemes in a multicentre trial.

Methods-Forty two strains of Enterobacteriaceae were distributed to 22 laboratories for identification by routine multipoint methods. Analysis of results enabled inter- and intralaboratory reproducibility of a variety of tests, and the ability of laboratories to identify individual organisms to be determined.

Results-Interlaboratory reproducibility of most of the biochemical tests was acceptable. The least reproducible tests, both within and between laboratories, were citrate utilisation, production of urease and $\beta$ galactosidase, detection of motility, and decarboxylation of lysine and ornithine. Inconsistent results for these tests were often associated with misidentified strains. Most laboratories performed identifications satisfactorily. Most isolates $(\mathbf{7 2 \cdot 1 \% )}$ were identified correctly to species level; $9.6 \%$ were incorrectly identified, and $6.4 \%$ could not be identified at all. The most difficult organisms to identify were Citrobacter freundii, Enterobacter cloacae, Hafnia alvei and Aeromonas hydrophila. Strains of Enterobacter, Serratia sp, and Providencia sp were difficult to speciate. Several laboratories could not identify organisms exhibiting at least one atypical biochemical reaction.

Conclusion-This study emphasises the need for quality control of media and reagents for multipoint identification of Gram negative enteric bacilli.
\end{abstract}

(F Clin Pathol 1993;46:637-641)

Two of the most important functions of a clinical microbiology laboratory are to identify bacteria and to determine their susceptibility to antimicrobial agents. Identifying Enterobacteriaceae permits recognition of particular pathogens (such as salmonellas), provides evidence of cross-infection or nosocomial infection, assists in determination of relapse or reinfection, and confirms intrinsic or inducible resistance to antimicrobial agents. ${ }^{12}$ Biochemical identification of the Enterobacteriaceae by multipoint inoculation on to agar media containing appropriate substrates has been described by many workers. $^{23-5}$ This technique is an accurate, cost effective alternative to the use of commercial kit systems ${ }^{26}$ and is fully compatible with susceptibility testing by the "break-point" method. ${ }^{7}$ Several workers have described a lack of biochemical test reproducibility within and between laboratories for both "traditional"8 and multipoint systems. ${ }^{56}$

\section{Methods}

Over a period of one year, 42 strains of Enterobacteriaceae and aeromonads (39 distinct organisms), including species commonly isolated in routine clinical laboratories, were distributed to 22 laboratories in the United Kingdom. Distributions 1, 2, and 3 each comprised 12 organisms, and results were returned by 17,19 , and 19 laboratories, respectively. Distribution 4 comprised six organisms and results were returned by 18 laboratories.

For the purpose of this study, individual test results were classed as "inconsistent" when they were at variance with most of the results returned by participating laboratories. Seven strains were known to give at least one "atypical" biochemical result. "True" identities of test strains were derived from the consensus of all results. These were confirmed using the API 20E system (API Laboratory Products, Basingstoke, England) and in every instance they concurred. Participants identified the strains by their routine multipoint inoculation technique, normally using substrates incorporated into agar plates but occasionally using supplementary tests in fluid media.

Of 19 laboratories returning a questionnaire, 13 centres used reconstituted dehydrated commercial Mast ID media (Mast Laboratories, Bootle, England) entirely; three centres used a combination of Mast ID media and "in-house" media, and three centres used "in-house" media exclusively. Four laboratories obtained results by the use of image analysis.

Identities assigned to test strains and their individual test reactions were returned to the authors for collation and analysis using a commercial suite of programs. 9 Individual test results were analysed to determine their interlaboratory reproducibility. Three organisms were distributed as duplicates so that a measure of intralaboratory reproducibility could also be made. Analysis of inconsistent results which might have contributed to misidentification was also undertaken. The identities of cultures used in the study were 
Table 1 Number of times biochemical reactions used in 22 different laboratories

\begin{tabular}{|c|c|}
\hline Biochemical reaction & Number \\
\hline $\begin{array}{l}\text { Deamination of tryptophan (TDA) } \\
\text { (or phenylalanine-PPA) } \\
\text { Production of urease }\end{array}$ & 18 \\
\hline $\begin{array}{l}\text { Acid from inositol } \\
\text { Citrate utilisation }\end{array}$ & 17 \\
\hline $\begin{array}{l}\text { Production of oxidase } \\
\text { Ornithine decarboxylation }\end{array}$ & 14 \\
\hline Production of indole (fluid) & 13 \\
\hline $\begin{array}{l}\text { Motility } \\
\text { Acid from sucrose and rhamnose } \\
\text { Lysine decarboxylation }\end{array}$ & 12 \\
\hline $\begin{array}{l}\text { Production of } \mathrm{H}_{2} \mathrm{~S} \\
\text { Malonate utilisation } \\
\text { Acid from glucose } \\
\text { Production of } \beta \text { galactosidase (plate ONPG) }\end{array}$ & 10 \\
\hline Acid from sorbitol & 9 \\
\hline $\begin{array}{l}\text { Acid from mannitol } \\
\text { Production of } \beta \text { glucuronidase } \\
\text { Hydrolysis of aesculin }\end{array}$ & 8 \\
\hline $\begin{array}{l}\text { Production of } \beta \text { galactosidase (fluid ONPG) } \\
\text { Hydrolysis of gelatin }\end{array}$ & 7 \\
\hline $\begin{array}{l}\text { Acid from amygdalin, dulcitol, lactose } \\
\text { and xylose } \\
\text { Production of acetoin (VP) }\end{array}$ & 6 \\
\hline $\begin{array}{l}\text { Production of indole (plate) } \\
\text { Acid from melibiose }\end{array}$ & 5 \\
\hline Production of deoxyribonuclease & 4 \\
\hline Acid from cellobiose & 3 \\
\hline $\begin{array}{l}\text { Acid from arabinose } \\
\text { Hydrolysis of arginine } \\
\text { Growth on Pseudomonas agar } \\
\text { Pigment production }\end{array}$ & 2 \\
\hline $\begin{array}{l}\text { Acid from maltose and adonitol } \\
\text { Oxidation of gluconate }\end{array}$ & 1 \\
\hline
\end{tabular}

not revealed to participating centres until all results for a particular distribution had been returned.

\section{Results}

A total of 37 tests was performed by the par-

Table 2 Interlaboratory reproducibility of test results

\begin{tabular}{|c|c|c|c|c|c|}
\hline \multirow[b]{2}{*}{ Test } & \multirow{2}{*}{$\begin{array}{l}\text { Total } \\
\text { number } \\
\text { of } \\
\text { returns }\end{array}$} & \multicolumn{4}{|c|}{$\begin{array}{l}\text { Number of strains }(n=42) \\
\text { showing complete agreement }\end{array}$} \\
\hline & & + & - & Total & $\%$ \\
\hline Melibiose & 17 & 21 & 20 & 41 & $97 \cdot 7$ \\
\hline Gelatin & 26 & 7 & 33 & 40 & $95 \cdot 2$ \\
\hline Xylose & 21 & 29 & 11 & 40 & $95 \cdot 2$ \\
\hline Oxidase $^{a}$ & 35 & 0 & 28 & 28 & $93 \cdot 3$ \\
\hline Lactose & 19 & 16 & 22 & 38 & $90 \cdot 5$ \\
\hline Sucrose & 47 & 21 & 17 & 38 & $90 \cdot 5$ \\
\hline Sorbitol & 36 & 23 & 15 & 38 & $90 \cdot 5$ \\
\hline Amygdalin & 21 & 14 & 24 & 38 & $90 \cdot 5$ \\
\hline$\beta$ glucuronidase & 27 & 6 & 32 & 38 & $90 \cdot 5$ \\
\hline Malonate & 38 & 10 & 26 & 36 & $85 \cdot 7$ \\
\hline Aesculin & 27 & 8 & 28 & 36 & $85 \cdot 7$ \\
\hline \multirow[t]{2}{*}{ Rhamnose } & 47 & 21 & 14 & 35 & $83 \cdot 3$ \\
\hline & 44 & b 24 & 14 & 38 & $90 \cdot 5$ \\
\hline PPA/TDA & 66 & 4 & 29 & 33 & $78 \cdot 6$ \\
\hline Indole fluid & 49 & 16 & 17 & 33 & $78 \cdot 6$ \\
\hline \multirow[t]{2}{*}{ Mannitol } & 30 & 22 & 10 & 32 & $76 \cdot 2$ \\
\hline & 29 & c 28 & 10 & 38 & $90 \cdot 5$ \\
\hline VP & 22 & 9 & 21 & 30 & $71 \cdot 4$ \\
\hline \multirow[t]{2}{*}{ Indole plate } & 22 & 12 & 17 & 29 & $69 \cdot 0$ \\
\hline & 18 & d 15 & 19 & 34 & $81 \cdot 0$ \\
\hline Hydrogen sulphide & 39 & 3 & 26 & 29 & $69 \cdot 0$ \\
\hline & 36 & e 4 & 34 & 38 & $90 \cdot 5$ \\
\hline Inositol & 67 & 6 & 22 & 28 & $66 \cdot 7$ \\
\hline Dulcitol & 24 & 6 & 22 & 28 & $66 \cdot 7$ \\
\hline Citrate & 55 & 14 & 13 & 27 & $64 \cdot 3$ \\
\hline ONPG fluid & 22 & 17 & 9 & 26 & 61.9 \\
\hline & 19 & b 27 & 11 & 38 & $90 \cdot 5$ \\
\hline Urea & 71 & 6 & 18 & 24 & $57 \cdot 1$ \\
\hline ONPG plate & 39 & 12 & 11 & 23 & $54 \cdot 8$ \\
\hline Motility & 41 & 16 & 4 & 20 & $47 \cdot 6$ \\
\hline Ornithine & 54 & 4 & 10 & 14 & $33 \cdot 3$ \\
\hline Lysine & 47 & 5 & 5 & 10 & $23 \cdot 8$ \\
\hline
\end{tabular}

${ }^{a}(n=30)$; results from laboratory numbers $24 b ; 15 c ; 23 d$; and $25 e$ omitted from analysis laboratory 24 used in-house media in combination with commercial media, laboratory 25 used in-house media exclusively. ticipating laboratories (table 1). The results of the 27 most commonly used tests were analysed: acid production from glucose was not included. Table 2 shows the number of times identical reactions were obtained with the same test strains (listed in table 3) in all laboratories (interlaboratory reproducibility). Interlaboratory reproducibility of tests detecting acid production from melibiose, xylose, lactose, sucrose, sorbitol and amygdalin was excellent (90.5-97.7\%). Rhamnose and mannitol fermentation tests seemed to be less reproducible $(83.3 \%$ and $76.2 \%$, respectively) but omission of one laboratory's data increased reproducibility to acceptable levels $(90.5 \%)$ in both cases. Fermentation of inositol and dulcitol were less reproducible tests $(66 \cdot 7 \%)$. Hydrolysis of gelatin and detection of $\beta$ glucuronidase and oxidase were very reproducible tests, as were the detection of $\beta$ galactosidase (from ONPG substrate) in fluid medium and hydrogen sulphide when data from laboratories 24 and 25, respectively, were excluded from analysis. Less reproducible tests $(71 \cdot 4 \%-85 \cdot 7 \%)$ included malonate utilisation, aesculin hydrolysis, deamination of tryptophan and production of indole and acetoin. The least reproducible tests $(23 \cdot 8 \%-64 \cdot 3 \%)$ were citrate utilisation, production of urease and $\beta$ galactosidase (in agar), detection of motility, and decarboxylation of lysine and ornithine.

Intralaboratory reproducibility was assessed by distributing the same three organisms on two separate occasions. Results were returned in a total of 43 instances (14 Providencia stuartii; 15 Morganella morganii, and 14 Aeromonas hydrophila). $M$ morganii was correctly identified by all 15 laboratories on both occasions. Three laboratories misidentified $P$ stuartii on one distribution but identified it correctly on the other. Three laboratories out of nine returning identifications were unable to identify $A$ hydrophila correctly on both distributions; three laboratories did not offer an identification for one of the distributions and the remaining two could not offer an identification for either.

The least reproducible tests were deamination of tryptophan (14/39 incorrect-eight for $P$ stuartii); motility ( $8 / 22$ incorrect); lysine decarboxylation (5/28 incorrect); indole fluid (4/30 incorrect-all $A$ hydrophila); citrate utilisation (3/34 incorrect-all $P$ stuartii); ornithine decarboxylation (4/31 incorrect); and urease ( $3 / 43$ incorrect). Single incorrect results were returned for fermentation of mannitol and inositol; production of $\beta$ galactosidase (plate and fluid); indole (plate); and production of acetoin. On four occasions laboratories obtained different identifications for duplicate organisms despite obtaining identical test results. Furthermore, tests for decarboxylation of lysine and ornithine, urease production, motility, inositol fermentation and citrate utilisation often gave inconsistent results for misidentified strains. These results broadly reflect the low interlaboratory reproducibility of these tests (table 2). Tests for detection of indole in fluid medium were 
Table 3 Identification of individual organisms: per cent of laboratories ( $n=17$ or 19) returning results

\begin{tabular}{|c|c|c|c|c|}
\hline \multirow[b]{2}{*}{ Organism } & \multicolumn{2}{|c|}{ Correct to: } & \multirow[b]{2}{*}{ Incorrect } & \multirow[b]{2}{*}{ No identification } \\
\hline & Species & Genus & & \\
\hline E coli 1 & $88 \cdot 2$ & $88 \cdot 2$ & $5 \cdot 9$ & 5.9 \\
\hline E coli 2 & $100 \cdot 0$ & $100 \cdot 0$ & & \\
\hline$E \operatorname{coli} 3 \mathbf{a}$ & 57.9 & $57 \cdot 9$ & $31 \cdot 6$ & $10 \cdot 5$ \\
\hline$E$ coli 4 & $100 \cdot 0$ & $100 \cdot 0$ & & \\
\hline$E$ coli 5 & $100 \cdot 0$ & $100 \cdot 0$ & & \\
\hline$E$ coli 6 b & $78 \cdot 9$ & 78.9 & $10 \cdot 5$ & $10 \cdot 5$ \\
\hline E cloacae 1 & $52 \cdot 9$ & $64 \cdot 7$ & $17 \cdot 6$ & $17 \cdot 6$ \\
\hline E cloacae 2 & $68 \cdot 4$ & $94 \cdot 7$ & $5 \cdot 3$ & \\
\hline E cloacae 3 & $42 \cdot 1$ & $78 \cdot 9$ & $10 \cdot 5$ & $10 \cdot 5$ \\
\hline E cloacae 4 & $63 \cdot 2$ & $73 \cdot 7$ & $15 \cdot 8$ & $10 \cdot 5$ \\
\hline Salmonella 1 & & $94 \cdot 1$ & & 5.9 \\
\hline Salmonella 2 & & $94 \cdot 7$ & $5 \cdot 3$ & \\
\hline Salmonella $3 \mathbf{b}$ & & $36 \cdot 8$ & $26 \cdot 3$ & $36 \cdot 8$ \\
\hline Salmonella 4 & & $89 \cdot 4$ & $10 \cdot 5$ & \\
\hline P stuartii 1 & $58 \cdot 8$ & $88 \cdot 2$ & 5.9 & $5 \cdot 9$ \\
\hline Pstuartii 2 & $73 \cdot 7$ & $84 \cdot 2$ & $10 \cdot 5$ & $5 \cdot 3$ \\
\hline P stuartii 3 & $57 \cdot 9$ & 78.9 & $15 \cdot 8$ & $5 \cdot 3$ \\
\hline$C$ freundii 1 & $64 \cdot 7$ & $64 \cdot 7$ & $35 \cdot 3$ & \\
\hline C freundii 2 & $68 \cdot 4$ & $73 \cdot 7$ & 10.5 & $15 \cdot 8$ \\
\hline C freundii 3 & $63 \cdot 2$ & $63 \cdot 2$ & $26 \cdot 3$ & 10.5 \\
\hline$E$ aerogenes 1 & $78 \cdot 9$ & $84 \cdot 2$ & $15 \cdot 8$ & \\
\hline$E$ aerogenes 2 & $78 \cdot 9$ & $89 \cdot 5$ & $10 \cdot 5$ & \\
\hline$E$ aerogenes $3 \mathrm{c}$ & $47 \cdot 4$ & $100 \cdot 0$ & & \\
\hline$M$ morganii 1 & $94 \cdot 1$ & $94 \cdot 1$ & & $5 \cdot 9$ \\
\hline$M$ morganii 2 & $94 \cdot 7$ & 94.7 & & $5 \cdot 3$ \\
\hline$A$ hydrophila 1 & 52.9 & 76.5 & $11 \cdot 8$ & $11 \cdot 8$ \\
\hline$A$ hydrophila 2 & $42 \cdot 1$ & $52 \cdot 6$ & 15.8 & 31.6 \\
\hline$P$ mirabilis 1 & $93 \cdot 3$ & $100 \cdot 0$ & & \\
\hline$P$ mirabilis $2 \mathbf{d}$ & $93 \cdot 3$ & 100.0 & & \\
\hline$S$ marcescens 1 & $52 \cdot 9$ & $88 \cdot 2$ & $11 \cdot 8$ & \\
\hline$S$ marcescens 2 & $42 \cdot 1$ & $94 \cdot 7$ & $5 \cdot 3$ & \\
\hline Kpneumoniae 1 & $76 \cdot 5$ & $94 \cdot 1$ & 5.9 & \\
\hline Kneumoniae 2 & $82 \cdot 4$ & 100.0 & & \\
\hline Koxytoca 1 & $88 \cdot 2$ & $100 \cdot 0$ & & \\
\hline Koxytoca 2 & $73 \cdot \overline{7}$ & 89.5 & & 10.5 \\
\hline$C$ diversus 1 & 89.5 & $94 \cdot 7$ & $5 \cdot 3$ & \\
\hline$C$ diversus 2 & 78.9 & $84 \cdot 2$ & 10.5 & $5 \cdot 3$ \\
\hline P vulgaris 1 & $84 \cdot 2$ & 94.7 & $5 \cdot 3$ & \\
\hline$P$ vulgaris 2 & $78 \cdot 9$ & $89 \cdot 5$ & $5 \cdot 3$ & $5 \cdot 3$ \\
\hline S sonnei e & $73 \cdot 7$ & $89 \cdot 5$ & $5 \cdot 3$ & $5 \cdot 3$ \\
\hline$H$ alvei & $57 \cdot 9$ & $63 \cdot 2$ & $21 \cdot 1$ & $15 \cdot 8$ \\
\hline P rettgerif & $26 \cdot 3$ & 52.6 & $21 \cdot 1$ & $26 \cdot 3$ \\
\hline
\end{tabular}

Atypical results for $\mathbf{a}$, indole; $\mathbf{b}, \beta$-galactosidase; $\mathbf{c}$, inositol; $\mathbf{d}$, hydrogen sulphide; $\mathbf{e}$, rhamnose; f, amygdalin much more reproducible, yet inconsistent results contributed to a high number of misidentified strains.

Table 3 illustrates the ability of participating laboratories to identify individual organisms; the overall performance of individual laboratories is shown in table 4. Several test results seemed to be inconsistent when com-

Table 4 Accuracy of identification

\begin{tabular}{|c|c|c|c|c|c|c|}
\hline \multirow{3}{*}{$\begin{array}{l}\text { Laboratory } \\
\text { Number }\end{array}$} & \multirow{3}{*}{$\begin{array}{l}\text { Number } \\
\text { of tests }\end{array}$} & \multirow{3}{*}{$\begin{array}{l}\text { Organisms } \\
\text { analysed }\end{array}$} & \multirow{2}{*}{\multicolumn{2}{|c|}{$\%$ correct to }} & \multicolumn{2}{|c|}{$\%$ of strains } \\
\hline & & & & & \multirow{2}{*}{$\begin{array}{l}\text { Not } \\
\text { identified }\end{array}$} & \multirow{2}{*}{$\begin{array}{l}\text { Misidentified } \\
\text { (to genus) }\end{array}$} \\
\hline & & & Species a & Genus & & \\
\hline 1 & 14 & 42 & $88 \cdot 1$ & $97 \cdot 6$ & & $2 \cdot 3$ \\
\hline 2 & 12 & 42 & $69 \cdot 0$ & $83 \cdot 3$ & $7 \cdot 1$ & $9 \cdot 5$ \\
\hline 3 & 16 & 42 & 92.9 & $97 \cdot 6$ & & $2 \cdot 4$ \\
\hline 4 & $18 / 21$ & 42 & $71 \cdot 4$ & $85 \cdot 7$ & $2 \cdot 4$ & 11.9 \\
\hline 5 & 16 & 30 & $66 \cdot 7$ & $73 \cdot 3$ & $13 \cdot 3$ & $13 \cdot 3$ \\
\hline 6 & 15 & 42 & $85 \cdot 7$ & 92.9 & - & $7 \cdot 1$ \\
\hline 8 & 11 & 30 & $86 \cdot 7$ & $96 \cdot 7$ & $3 \cdot 3$ & \\
\hline 9 & 16 & 42 & $57 \cdot 1$ & $71 \cdot 4$ & $16 \cdot 7$ & 11.9 \\
\hline 10 & 15 & 12 & $66 \cdot 7$ & $66 \cdot 7$ & 33.3 & \\
\hline 11 & 16 & 42 & $69 \cdot 0$ & $83 \cdot 3$ & $9 \cdot 5$ & $7 \cdot 1$ \\
\hline 12 & 15 & 42 & $76 \cdot 2$ & 90.5 & $7 \cdot 1$ & $2 \cdot 4$ \\
\hline 14 & 14 & 42 & 92.9 & 92.9 & - & $7 \cdot 1$ \\
\hline 15 & 15 & 42 & $88 \cdot 1$ & 92.9 & $4 \cdot 8$ & $2 \cdot 4$ \\
\hline 16 & 17 & 42 & $66 \cdot 7$ & $85 \cdot 7$ & $4 \cdot 8$ & $9 \cdot 5$ \\
\hline 18 & 9 & 34 & $44 \cdot 1$ & 52.9 & 23.5 & 23.5 \\
\hline 19 & 12 & 12 & $83 \cdot 3$ & 91.7 & & $8 \cdot 3$ \\
\hline 22 & 19 & 42 & $83 \cdot 3$ & $88 \cdot 1$ & $2 \cdot 4$ & $9 \cdot 5$ \\
\hline 23 & & 42 & $78 \cdot 6$ & 92.9 & & $7 \cdot 1$ \\
\hline 24 & $14 / 17$ & 30 & $73 \cdot 3$ & $93 \cdot 3$ & & 6.7 \\
\hline 25 & 17 & 30 & $70 \cdot 0$ & $80 \cdot 0$ & & $20 \cdot 0$ \\
\hline 26 & 6 & 30 & $23 \cdot 3$ & $60 \cdot 0$ & 13.3 & $26 \cdot 7$ \\
\hline 44 & 6 & 18 & $11 \cdot 1$ & 38.9 & $22 \cdot 2$ & 38.9 \\
\hline
\end{tabular}

a Includes Salmonella spp.
Table 5 Incidence of inconsistent results possibly contributing to misidentification

\begin{tabular}{|c|c|c|c|}
\hline \multirow[b]{2}{*}{ Biochemical reaction } & \multicolumn{2}{|c|}{$\begin{array}{l}\text { Number of test results } \\
\text { possibly contributing to: }\end{array}$} & \multirow[b]{2}{*}{ Tota } \\
\hline & $\begin{array}{l}\text { Identification } \\
\text { to genus only }\end{array}$ & $\begin{array}{l}\text { Incorrect } \mathbf{a} \\
\text { identification }\end{array}$ & \\
\hline Ornithine & 7 & 23 & 30 \\
\hline Lysine & 7 & 22 & 29 \\
\hline Urea & 7 & 17 & 24 \\
\hline Motility & 5 & 16 & 21 \\
\hline Inositol & 8 & 13 & 21 \\
\hline Citrate & 1 & 15 & 16 \\
\hline Indole (fluid) & 5 & 8 & 13 \\
\hline PPA/TDA & 6 & 3 & 9 \\
\hline ONPG (plate) & 3 & 5 & 8 \\
\hline Indole (plate) & 3 & 5 & 8 \\
\hline ONPG (fluid) & 3 & 4 & 7 \\
\hline Voges Proskauer & 2 & 4 & 6 \\
\hline Malonate & - & $5 \mathrm{~b}$ & 5 \\
\hline Sorbitol & - & 4 & 4 \\
\hline Oxidase & - & 4 & 4 \\
\hline Hydrogen sulphide & $1 \mathrm{c}$ & $3 \mathrm{c}$ & 4 \\
\hline Aesculin & 1 & 3 & 4 \\
\hline Dulcitol & 2 & 2 & 4 \\
\hline Gelatin & - & 3 & 3 \\
\hline Amygdalin & 1 & 2 & 3 \\
\hline Rhamnose & - & 2 & 2 \\
\hline Mannitol & 1 & 1 & 2 \\
\hline Lactose & 2 & - & 2 \\
\hline Sucrose & - & 1 & 1 \\
\hline Melibiose & - & 1 & 1 \\
\hline Xylose & - & 1 & 1 \\
\hline$\beta$ glucuronidase & - & - & 0 \\
\hline
\end{tabular}

Includes no identification; b four from Laboratory 18; Laboratory 25 (in-house media)

pared with those obtained by most of the other participating laboratories. When these were correlated with misidentified strains, results which may have contributed to misidentification became apparent (table 5).

\section{Discussion}

There are several reasons why incorrect identifications occur. Firstly, transcription errors, or errors in performing individual tests, may be made; in some cases such errors may be due to poor quality test media. This study identified certain laboratories that consistently performed individual tests badly. Secondly, too few tests or tests with low discriminatory values are sometimes used. Again, laboratories using such tests were identified. Finally, there may be errors in the database used to interpret results. Poor test reproducibility can be attributed to many factors, but individual inconsistent results do not always contribute towards misidentification. A reliable database sympathetic towards test conditions and subjective reactions should be capable of interpreting results that are technically correct. Without access to an individual's database, it is impossible to determine what single factor contributes towards the inability to identify an organism.

Inconsistent results for citrate utilisation and lysine or ornithine decarboxylation occurred with a wide range of organisms and included both false positive and false negative reactions. By definition, utilisation of citrate is a very selective test. As with all assimilation reactions, the test is inoculum dependent and inocula should be modified for the medium formulation in use. We find that the test is also affected by storage of the inoculated plates at $+4^{\circ} \mathrm{C}$ before incubation-for 
example, over the weekend-after which many organisms will appear falsely negative. This may be overcome by incubating plates at $30^{\circ} \mathrm{C}$ continuously. We obtained better results when "in-house" lysine plates were incubated in anaerobic conditions. ${ }^{6}$ It is recommended that Mast ID decarboxylase media be incubated aerobically. ${ }^{10}$ This results in a deamination rather than a decarboxylation $^{11}$ and is accounted for in the database. False positive reactions can occur as a result of deamination of peptones. The test described by Pease ${ }^{12}$ is based on diauxic growth: glucose is first fermented, followed by decarboxylation of either lysine or ornithine. The results of the test thus depend on the ability of the organism to utilise glucose. If strains are slow in fermenting glucose or in inducing decarboxylases, false negative reactions may occur. Overincubation can produce false positive results, especially with strains of Klebsiella spp and Enterobacter spp. There does not seem to be any single incubation period which completely satisfies all test strains: Limb and Wheat found an optimal time period of about 15 hours. ${ }^{13}$ Plates must then be read immediately before diffusion occurs. Incubation temperature also seems to affect results.

The formulation of urease media depends on the incubation times used and the sensitivity required. Thus Mast urea media, a derivation of Christensen's urea agar, ${ }^{14}$ detects weak urease production in strains of Enterobacter $\mathrm{sp}$, Klebsiella $\mathrm{sp}$, and Citrobacter $\mathrm{sp}$. Other formulations (such as that of Rustigian and Stuart ${ }^{15}$ ) only allow strains of Proteus sp, $M$ morganii (and occasionally Yersinia $\mathrm{sp}$,) to produce detectable urease. As determined by Wheat and Pease, ${ }^{6}$ urease test results were in complete agreement for members of the genus Proteus, all of which gave positive reactions, but inconsistent results were obtained with strains of Citrobacter, Enterobacter, Klebsiella and Providencia. Again, laboratories using commercial media will incubate urea plates aerobically. Under these conditions, colour reactions tend to diffuse into each other. We find that by incorporating potassium nitrate $(1 \mathrm{~g} / \mathrm{l})$ into the medium and incubating anaerobically, colour diffusion is prevented and positive reactions are limited to Proteus sp, Morganella sp, and Klebsiella sp. ${ }^{16}$

Clayton et al reported on the difficulty of assessing an organism's motility, ${ }^{5}$ and Wheat and Pease reported that inconsistent motility results in their study were caused by strains of diminished motility being interpreted as nonmotile. ${ }^{6}$ Most discrepant motility results in our study also comprised false negative results. Motility depends on the medium used, the condition of the organism, and the temperature of incubation. Accuracy of results can be improved by incubating motility tests at different temperatures, ${ }^{5}$ and Limb and Wheat found that motility was better assessed at $30^{\circ} \mathrm{C} .^{13}$ Commercial media include triphenyl tetrazolium chloride (TTC) as an indicator of motility, and certain organ- isms may be unable to break down TTC, thus appearing as falsely negative in this test.

The choice of solid or fluid medium depends on a balance between sensitivity and specificity. On the one hand, fluid media are preferable because of increased sensitivity, but on the other, they are more prone to contamination. A strain of $P$ rettgeri, known to be indole positive and $\beta$ galactosidase negative, ${ }^{17}$ was included in one distribution. Most laboratories $(70 \%)$ found the organism to be indole positive in fluid media but no laboratory found it positive on agar. On the other hand, the organism was found to be $\beta$ galactosidase negative on agar; $17 \%$ of laboratories recorded positive results using liquid media. Seventeen laboratories tested both $\beta$ galactosidase and indole. Of these, five used fluid media and four agar. The remaining eight used a combination of solid and fluid media (mainly $\beta$ galactosidase plate together with indole fluid). We suggest that there are clear advantages in using fluid media for the determination of both indole production and the presence of $\beta$ galactosidase. The fluid medium can also be used as the suspending fluid for inoculation of agar plates; weak $\beta$ galactosidase producers $-H$ alvei and $S$ marcescens-are more easily detected; reactions do not have to be read immediately; and there are financial savings to be made.

Wheat and Pease $^{6}$ found only $67 \%$ agreement between results of inositol fermentation tests. Reproducibility of this test in the present study was low, and we have observed that pigment production is enhanced on this medium and that this may result in false positive reactions being recorded.

Three laboratories obtained false negative oxidase results with a strain of $A$ hydrophila. In every case this was associated with that particular laboratory failing to make an identification. The possibility exists that these laboratories are performing oxidase tests on organisms growing on media containing a source of fermentable carbohydrate.

Identification of "atypical" organisms depends on the discriminatory value of the atypical test(s); the relative "difficulty" of the identification in the first place; and on the flexibility of the database. Thus atypical hydrogen sulphide ( $P$ mirabilis) and rhamnose ( $S$ sonnei) results probably did not affect identification because of their low discriminatory value. Laboratories found biochemically typical isolates of $P$ rettgeri and $E$ aerogenes difficult to identify to species level; this was further compounded by atypical amygdalin and inositol reactions, respectively. An atypical result for a test with a high discriminatory value was an extreme test of a laboratory's database, and many found problems with an indole negative $E$ coli, a $\beta$ galactosidase negative $E$ coli, and a $\beta$ galactosidase positive Salmonella sp. These three organisms were all recovered from clinical material.

Individual laboratories consistently returned "erroneous" results for fermentation of rhamnose, sorbitol, mannitol and dulcitol; for detection of $\beta$ glucuronidase, hydrogen 
sulphide, production of $\beta$ galactosidase (fluid), indole (plate) and acetoin; and for malonate utilisation. Laboratories returning inconsistent results for rhamnose, sorbitol, hydrogen sulphide and production of $\beta$ galactosidase (fluid) used "in-house" media either partly or exclusively, and this could have accounted for differences between their results and those obtained by most Mast media users. These inconsistent results should not affect identification if the individual's database reflects results obtained with their system under particular defined conditions. Laboratories returning inconsistent results for mannitol and dulcitol fermentation took corrective action on receiving an intermediate breakdown of their results; laboratories returning inconsistent results for $\beta$ glucuronidase, production of indole (plate) and acetoin, and malonate utilisation did not. Four laboratories which were performing satisfactorily added tests or modified media as a result of the quality control distributions: one increased the number of tests used from 17 to 21 throughout the year. The two laboratories using only six tests are now reviewing their systems.

Participating laboratories used a variety of tests $(n=37)$ and varied in their ability to identify strains. Previous workers ${ }^{5}$ have shown that the greater the number of tests used in a multipoint identification scheme, the better the degree of differentiation of the taxa. Previous reports of multipoint identification of Enterobacteriaceae ${ }^{13-5}$ have used schemes based on between nine and 20 reactions. Predictably, laboratories using fewer tests (six to nine) performed less well than laboratories using 11 tests or more. Ability to identify strains depends, in part, on the discriminatory nature of chosen tests. Some laboratories using 11 or 12 tests identified more strains to the correct genus than other laboratories using 19 tests. Best speciation, however, was obtained by laboratories using 14 or 16 tests.

The overall conclusion of this study is that, despite interlaboratory variation in individual test results, most laboratories performed identifications satisfactorily. The results for 768 organism/laboratory combinations were analysed. Most organisms (554 or $72 \cdot 1 \%$ ) were identified correctly to species level. A further $73(9.5 \%)$ were identified to genus level only; 20 proved to be Enterobacter sp and 15 Serratia sp. Eighteen (2.3\%) were identified to the correct genus but to the incorrect species; of these, nine were Enterobacter sp and seven were Providencia sp. Seventy four $(9 \cdot 6 \%)$ were incorrectly identified and 49 $(6 \cdot 4 \%)$ could not be identified at all. Most of these strains were biochemically atypical or were strains of $E$ cloacae, $C$ freundii, $H$ alvei or $A$ hydrophila. Laboratories generally performed less well with organisms exhibiting "atypical" biochemical reactions. A strain of Proteus mirabilis not producing hydrogen sul- phide and a strain of sonnei not fermenting rhamnose were generally identified correctly. Laboratories performed poorly, however, with an indole negative $E$ coli, a $\beta$ galactosidase negative $E$ coli, a $\beta$ galactosidase positive Salmonella $\mathrm{sp}$, and an amygdalin positive $P$ rettgeri. All laboratories could identify a strain of $E$ aerogenes not fermenting inositol to genus level but many had problems speciating this organism.

Because of the wide diversity of the number of tests used, there is no one identification scheme for Enterobacteriaceae. Different laboratories have different expectations of their identification systems: some aim for full identification, others are content to "screenout" certain genera. All laboratories, however, must be confident that they are achieving reproducible and reliable biochemical reactions that lead to results which accord with those published. Only enthusiastic quality control measures can help laboratories achieve this goal.

The authors acknowledge the sponsorship of the British Society for Microbial Technology and thank all centres who participated in the study. Please contact the authors for details of quality control schemes.

1 Pease AA, Harris DM. Salmonellas as a cause of urinary infection. Comm Dis Rep 1983;15.

2 Pease AA, Wheat PF, Harris DM. Antimicrobial susceptibility testing and biochemical identification using multipoint inoculation: 5 years' experience. Med Lab Sci point inoculation

3 Chadwick P, Delisle GJ, Byer M. Biochemical identification of hospital enterobacteria by replica agar plating. Can $\mathcal{F}$ Microbiol 1974;20:1653-64

4 Funnell GR, Parkinson DL, Bradbury R. Biochemical identification of enterobacteriaceae by multipoint inoculation using Mast ID media. Aust $\mathcal{f}$ Med Lab Sci 1986; 7:75-7.

5 Clayton P, Feltham RKA, Mitchell CJ, Sneath PHA. Constructing a database for low cost identification of Gram negative rods in clinical laboratories. $\mathcal{f}$ Clin Pathol 1986;39:798-802.

6 Wheat PF, Pease AA. Identification of the enterobacteriaceae: report of the British Society for Multipoint Technology collaborative study. Med Lab Sci 1989; 46:179-85.

7 Waterworth PM. Sensitivity testing by the breakpoint method. F Antimicrob Chemother 1981;7:117-26.

8 Sneath PHA. Test reproducibility in relation to identification. Int $\mathcal{F}$ Syst Bacteriol 1974;24:508-23.

9 Magee JT, Wheat PF, Spencer RC. Microcomputer based infection surveillance: the Microbe Base systems. Binary 1990;2:83-8.

10 Maccani JE. Aerobically incubated medium for decarboxylase testing of Enterobacteriaceae by replica-plating methods. F Clin Microbiol 1979;10:940-2.

11 Moller V. Simplified tests for some amino acid decarboxylases and for the arginine dihydrolase system. Acta Pathol Microbiol Immunol Scand 1955;36:158-72.

12 Pease AA. Biochemical identification of the enterobacteriaceae using a multipoint inoculation system. Med Lab aceae using a multipoi

13 Limb DI, Wheat PF. Evaluation of a commercial automated system for the identification of Gram-negative enteric bacilli. Eur $\mathcal{F}$ Clin Microbiol Infect Dis 1991;10: 749-52.

14 Christensen WB. Urea decomposition as a means of differentiating Proteus and paracolon cultures from each other and from salmonella and shigella. $\mathcal{f}$ Bacteriol 1946;52:461-6.

15 Rustigian R, Stuart CA. The biochemical and serological relationships of the organisms of the genus Proteus. $f$ Bacteriol 1945;49:419-36.

16 Faiers M, George R, Jolly J, Wheat P. Identification of Enterobacteriaceae. In: Multipoint methods in the clinical laboratory: a handbook London: Public Health Laboralaboratory: a handbook Londo
tory Service, 1991:56-68.

17 Snell JS. Bacteriological characterization tests. In: Snell JJS, Farrell ID, Roberts C, eds. Quality control: principles and practice in the microbiology laboratory. 